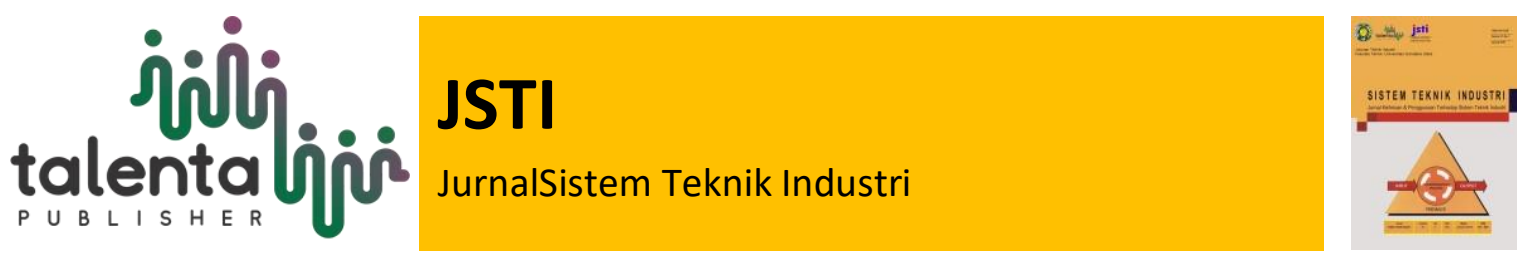

\title{
Perencanaan Kebutuhan Sumber Daya Manusia untuk Mempercepat Waktu Respon di Instalasi Gawat Darurat (IGD) dengan Metode Discrete Event Simulation (Studi Kasus: RSU HKBP Balige)
}

\author{
Desi Simorangkir dan Yosef Manik \\ Program Studi Manajemen Rekayasa, Fakultas Teknologi Industri, Institut Teknologi Del
}

\begin{abstract}
One of the performance indicators to assess the speed of service in the emergency department is the response time, which is the time between the arrival of the patient in the emergency room until the patient is treated by a doctor. The standard response time based on the Decree of the Minister of Health of the Republic of Indonesia Number 856 of 2009 is a maximum of 5 minutes. The response time is strongly influenced by the adequacy of human resources, in this case physicians and nurses. This article shows the use of discrete event simulation in planning optimal human resource needs in the Balige HKBP General Hospital emergency room in relation to minimizing response time. Simulation models are developed using Arena simulation software. The results of this study indicate that the average response time in the Emergency Room at Balige HKBP General Hospital can be reduced from 8.61 minutes to 4.14 minutes, and the maximum response time from 26.30 minutes to 14.09 minutes by allocating of 2 physicians and 3 nurses per shift.
\end{abstract}

Keyword: Human Resources, Emergency Department, Response Time, Discrete Event Simulation, Arena

\begin{abstract}
Abstrak: Salah satu indikator performansi untuk menilai kecepatan pelayanan di instalasi gawat darurat (IGD) adalah waktu respon yaitu waktu antara kedatangan pasien di IGD hingga pasien ditangani oleh dokter. Standar waktu respon berdasarkan Keputusan Menteri Kesehatan Republik Indonesia Nomor 856 Tahun 2009 adalah maksimum 5 menit. Waktu respon sangat ditentukan oleh kecukupan sumber daya manusia, dalam hal ini dokter dan perawat. Artikel ini menunjukkan penggunaan simulasi disktrit dalam merencanakan kebutuhan dokter dan perawat yang optimal di IGD RSU HKBP Balige untuk meminimumkan waktu respon. Model simulasi dikembangkan dengan menggunakan perangkat lunak simulasi Arena. Hasil penelitian ini menunjukkan bahwa waktu respon rata-rata di IGD RSU HKBP Balige dapat diturunkan dari 8,61 menit menjadi 4,14 menit, serta waktu respon maksimum dari 26,30 menit menjadi 14,09 menit dengan sumber daya manusia sebanyak 3 dokter dan 6 perawat per shift.
\end{abstract} Kata Kunci: Sumber Daya Manusia, Instalasi Gawat Darurat, Waktu Respon, Discrete Event Simulation, Arena

Received 5 mei 2020 | Revised 20 Mei 2020 | Accepted 2 Juni 2020

*Corresponding author at: Institut Teknologi Del, Toba, Indonesia

E-mail address: Yosef Manik<yosef.manik@del.ac.id> 


\section{Pendahuluan}

Berdasarkan data Direktorat Jenderal Bina Pelayanan Medik Depkes, kunjungan pasien ke IGD di seluruh Indonesia pada tahun 2007 tercatat sebanyak 4.402.205 (13,3\% dari total seluruh kunjungan di RSU) dari 1.033 jumlah RSU yang ada (Menkes RI, 2009). Permintaan pasien terhadap pelayanan IGD semakin meningkat. Data kunjungan pasien di IGD RSU HKBP Balige tahun 2015 sebanyak 8.437 orang dan pada tahun 2016 sebanyak 11.801 orang, meningkat $40 \%$ dari tahun sebelumnya. Pada tahun 2017 mencapai 13.434 orang, meningkat $14 \%$ dari tahun 2016. Jumlah yang signifikan ini menunjukkan bahwa pelayanan pasien gawat darurat memerlukan perhatian yang cukup besar [1] .

Kondisi pasien gawat darurat yang seringkali membutuhkan penanganan segera sehingga IGD harus selalu memberikan pelayanan secara cepat dan tepat. Untuk itu perlu adanya standar dalam memberikan pelayanan gawat darurat sesuai dengan kompetensi dan kemampuan rumah sakit sehingga dapat menjamin suatu penanganan gawat darurat dengan response time yang cepat dan penanganan yang tepat. Semua itu dapat dicapai antara lain dengan meningkatkan sarana, prasarana, sumber daya manusia dan manajemen Instalasi Gawat Darurat Rumah Sakit sesuai dengan standar .

Salah satu ukuran performansi untuk menilai kecepatan pelayanan di IGD adalah waktu respon (response time) atau waktu tanggap. Waktu respon adalah waktu antara pasien datang ke IGD hingga pasien ditangani oleh dokter. Standar waktu respon berdasarkan Keputusan Menteri Kesehatan Republik Indonesia Nomor 856 Tahun 2009 adalah pasien gawat darurat harus ditangani paling lama 5 (lima) menit setelah sampai di IGD. Pelayanan yang terlambat dapat menyebabkan waktu respon/ waktu tunggu pasien menjadi lama, pasien meninggalkan IGD tanpa diperiksa, kondisi pasien bertambah buruk karena tidak ditangani dengan cepat, dan terjadinya kejadian yang dapat membahayakan nyawa pasien. Berdasarkan observasi awal di IGD RSU HKBP Balige selama penelitian pendahuluan, dari 212 kasus pasien IGD, terdapat 50 kasus (23,6 $\%)$ di mana waktu responnya melebihi 5 menit. Ada berbagai faktor yang mempengaruhi waktu respon di IGD termasuk sumber daya manusia [2]. Sumber daya manusia yang dimiliki oleh RSU HKBP Balige, baik tenaga medis maupun tenaga administrasi, terbatas. Sementara itu terdapat ketidakpastian kedatangan pasien baik dari segi jumlah maupun tingkat kegawatan yang dialami. Hal ini yang membuat perencanaan komposisi sumber daya manusia di IGD RSU HKBP Balige menjadi rumit.

Dari keadaan tersebut, maka peneliti tertarik untuk menganalisis waktu respon terhadap pasien di IGD RSU HKBP Balige dan mencoba menyelesaikan permasalahan waktu respon agar menjadi cepat dan sesuai standar. Metode simulasi telah digunakan oleh banyak peneliti untuk meniru perilaku dari sistem pelayanan kesehatan untuk mengevaluasi kinerja sistem tersebut dan menganalisis hasil dari berbagai skenario. Dalam mengatasi permasalahan waktu respon yang tidak tepat, peneliti menggunakan pendekatan Discrete Event Simulation (DES) karena kemampuannya dalam memodelkan sistem yang bersifat kompleks, dinamis, diskrit, dan stokastik [3][4][5]. Beberapa penelitian telah yang menggunakan DES dalam perencanaan sumber daya medis [6][7][8]. Dalam artikel-artikel tersebut, sistem dan proses pelayanan pasien IGD di rumah sakit di Jerman, Singapura, dan Hongkong disimulasikan ke dalam sebuah model DES untuk menghasilkan perencanaan sumber daya yang optimal.

Dalam artikel ini akan dipaparkan bagaimana DES digunakan sebagai alat analisis untuk menentukan kebutuhan sumber daya manusia di IGD RSU HKBP Balige. Hasil yang diperoleh diharapkan dapat membantu IGD RSU HKBP Balige membuat keputusan mengenai jumlah dokter dan perawat yang optimal dalam mencapai target standard waktu respon sesuai peraturan yang berlaku. 


\section{Metodologi Penelitian}

Tahapan dilakukan secara berurutan mulai dari studi lapangan dan studi literatur sampai pada penarikan kesimpulan. Adapun tahapan metodologi dalam penelitian ini adalah:

1. Analisis permasalahan sistem

Sistem di IGD RSU HKBP Balige diidentifikasi dan dianalisis melalui obsevasi wawancara dengan Kepala/Petugas Medis IGD RSU HKBP Balige. Dari tahap ini diperoleh konteks, karakteristik dan permasalahan sistem, serta pemetaan sistem dalam hal input, proses dan output. Dari analisis ini pula dapat dirincikan tujuan yang diharapkan dari penelitian ini serta batasan dan asumsi yang ada. Secara umum, alur proses penanganan pasien di IGD RSU HKBP Balige terdiri dari: (a) triase; (b) pemeriksaan perawat; (c) pemeriksaan dokter; (d) pemeriksaan tambahan; (e) diagnosa; dan (f) tindak lanjut. Triase merupakan penilaian, pemilahan dan pengelompokan penderita yang akan mendapatkan penanganan medis dan pengambilan keputusan dalam menentukan tingkat kegawatdaruratan pasien. Pasien yang memiliki tingkat kegawatdaruratan yang lebih tinggi akan diprioritaskan. Pemeriksaan perawat pada IGD RSU HKBP Balige dilakukan setelah tingkat kegawatdaruratan ditentukan. Dokter melakukan anamnese (wawancara dengan pasien terkait keluhan yang dimiliki), pemeriksaan fisik, menentukan pemeriksaan penunjang dan tindak lanjut perawatan yang diperlukan sehubung dengan penyakit pasien, kemudian menuliskannya pada status rekam medik. Dokter memberikan tindakan medis dan terapi sementara pada pasien yang memerlukannya, kemudian menuliskan tindakan yang telah dilakukan tersebut. Apabila diperlukan, dokter IGD melakukan konsultasi dengan dokter spesialis. Pemeriksaan penunjang dapat berupa pemeriksaan laboratorium, radiografi, elektrokardiogram (EKG) dan pemeriksaan penunjang lainnya yang dilakukan untuk menunjang diagnosa agar lebih akurat. Diagnosa dilakukan untuk menyimpulkan penyakit pasien dan tindakan yang dibutuhkan selanjutnya. Tindak lanjut perawatan merupakan proses akhir dari pelayanan pasien IGD. Tindak lanjut perawatan dapat berupa rawat inap (opname), pengalihan pasien ke poliklinik, merujuk pasien, mengoperasi pasien, atau membawa ke kamar jenazah.

2. Perancangan model konseptual

Perancangan model koseptual dilakukan berdasarkan proses pelayanan pasien di IGD RSU HKBP Balige. Terdapat tiga faktor yang akan menjadi fokus penelitian ini, yaitu jumlah dokter IGD yang terbatas, jumlah perawat IGD yang terbatas dan total waktu pelayanan pasien yang lama. Jumlah dokter IGD dan perawat IGD akan digunakan sebagai input simulasi, sedangkan waktu respon dan total waktu pelayanan pasien akan diamati dengan menambahkan entitas waktu respon dan total waktu pelayanan pasien

3. Pengumpulan data

Pengumpulan data/informasi dilakukan melalui wawancara dengan Kepala/Petugas Medis IGD RSU HKBP Balige, observasi langsung di IGD RSU HKBP Balige dan penelusuran dokumen Standar Prosedur Operasional (SPO) IGD RSU HKBP Balige. Informasi yang dikumpulkan pada tahap ini terdiri dari profil RSU HKBP Balige, profil IGD RSU HKBP Balige dan sistem pelayanan pasien di IGD RSU HKBP Balige. Variabel-variabel yang menjadi masukan pada model simulasi yang akan dibangun antara lain terdiri dari: (a) jumlah sumber daya, yaitu jumlah dokter, perawat dan bed yang ada atau tersedia di IGD; (b) waktu antar kedatangan pasien, yaitu selisih waktu kedatangan antar satu pasien dengan pasien lainnya; (c) waktu proses triase; (d) persentase jenis tingkat kegawatdaruratan pasien berdasarkan hasil proses triase; (e) waktu antara pasien tiba di IGD hingga pasien menempati bed; (f) waktu proses pemeriksaan oleh perawat dan dokter serta tindakan lanjutan; (g) persentase pasien meninggal dan tidak meninggal; (h) persentase pasien yang mengikuti pemeriksaan penunjang; (i) waktu proses pemeriksaan penunjang; (j) persentase konsultasi dokter IGD ke dokter spesialis; (k) waktu proses konsultasi, diagnose, dan advise dokter spesialis; (l) persentase jumlah pasien untuk tidak lanjut perawatan; dan $(m)$ wakut tunggu pemindahan pasien untuk setiap jenis tidak lanjut perawatan.

4. Pembuatan model simulasi

Pembuatan model simulasi dilakukan dengan menggunakan perangkat lunak simulasi Rockwell Arena [9]. Pembuatan model ini didasarkan pada model konseptual yang dilakukan penyederhanaan, karena model simulasi sistem akan sangat kompleks jika dimodelkan seluruhnya. Sebelum model simulasi dijalankan, parameter simulasi ditentukan terlebih dahulu. Parameter 
simulasi yang akan ditentukan nilainya adalah waktu simulasi (replication length) dan jumlah replikasi (number of replication).

5. Eksperimen dan validasi

Eksperimen dilakukan untuk melihat pengaruh perubahan jumlah sumber daya manusia terhadap waktu respon dan total waktu pelayanan di IGD RSU HKBP Balige. Eksperimen didesain menggunakan desain faktorial $2^{\mathrm{k}}$ dengan $\mathrm{k}=2$ faktor input, yaitu dokter dan perawat. Eksperimen dilakukan dengan menjalankan simulasi dengan kombinasi faktor input sesuai dengan desain matriks $2^{\mathrm{k}}$. Validasi untuk model simulasi Pelayanan Pasien IGD RSU HKBP Balige dilakukan dengan validasi model konseptual dengan pihak manajemen IGD RSU HKBP Balige dan validasi tingkat signifikansi kemiripan antara data jumlah pasien pada simulasi dengan jumlah pasien pada sistem nyata.

\section{Hasil dan Pembahasan}

\subsection{Sistem Pelayanan IGD RSU HKBP Balige}

Input IGD RSU HKBP Balige adalah pasien IGD. Proses pelayanannya sebagian telah diurakan pada Bagian 2. Sedangkan outputnya adalah pasien yang telah diberi tindakan dan siap diarahkan ke bagian lain (pulang, poliklinik, operasi, rujuk, opname, kamar jenazah). Sebagaimana diuraikan pada bagian sebelumnya pula, penanganan medis dan pengambilan keputusan ditentukan dari tingkat kegawatdaruratan pasien. Tingkat kegawatan pasien dibagi menjadi empat, yaitu merah, kuning, hijau dan hitam dengan deskripsi pada Tabel 1.

Tabel 1: Tingkat kegawatdaruratan pasien

\begin{tabular}{cl}
\hline Tingkat Kegawatdaruratan & \multicolumn{1}{c}{ Deskripsi } \\
\hline Merah & Pasien gawat darurat \\
Kuning & Pasien gawat tidak darurat atau darurat tidak \\
Hijau & gawat \\
Hitam & Pasien tidak gawat tidak darurat \\
\hline
\end{tabular}

Pasien dengan tingkat kegawatdaruratan merah merupakan pasien yang berada dalam keadaan gawat dan terancam nyawa atau anggota badannya bila tidak mendapatkan pertolongan secepatnya. Pasien dengan tingkat kegawatdaruratan kuning merupakan pasien kondisi gawat tidak darurat atau darurat tidak gawat. Tindak lanjut perawatan pasien dengan tingkat kegawatdaruratan kuning dapat berupa operasi, opname, poliklinik, rujuk dan pulang. Pasien dengan tingkat kegawatdaruratan hijau merupakan pasien kondisi tidak gawat tidak darurat. Tindak lanjut perawatan pasien dengan tingkat kegawatdaruratan hijau adalah setelah mendapat hasil diagnosa, pasien dapat langsung pulang atau dialihkan ke poliklinik. Pasien dengan tingkat kegawatdaruratan hitam merupakan pasien kondisi Death on Arrival (DOA), yaitu pasien yang tiba di IGD sudah dalam kondisi meninggal. Tindak lanjut untuk pasien untuk tingkat kegawatdaruratan hitam adalah setelah pasien dinyatakan meninggal oleh dokter, pasien dibawa ke kamar jenazah. Permasalahan yang ditemukan di IGD RSU HKBP Balige adalah waktu respon yang lama, yaitu melebihi standar yang telah ditetapkan ( $>5$ menit).

\subsection{Model Konseptual}

Model konseptual awal dilakukan berdasarkan proses pelayanan pasien IGD RSU HKBP Balige Tingkat kegawatdaruratanan pasien yang berbeda-beda akan mempengaruhi waktu respon pasien karena dokter atau perawat akan memprioritaskan pasien dengan tingkat kegawatdaruratan yang lebih tinggi. Model konseptual yang telah dibuat sebelumnya diberikan penyesuaian agar dapat digunakan saat pembuatan model simulasi. Jumlah dokter IGD dan perawat IGD akan digunakan sebagai input simulasi, sedangkan waktu respon dan total waktu pelayanan pasien akan diamati 
dengan menambahkan entitas waktu respon dan total waktu pelayanan pasien yang dapat dilihat pada Gambar 1:

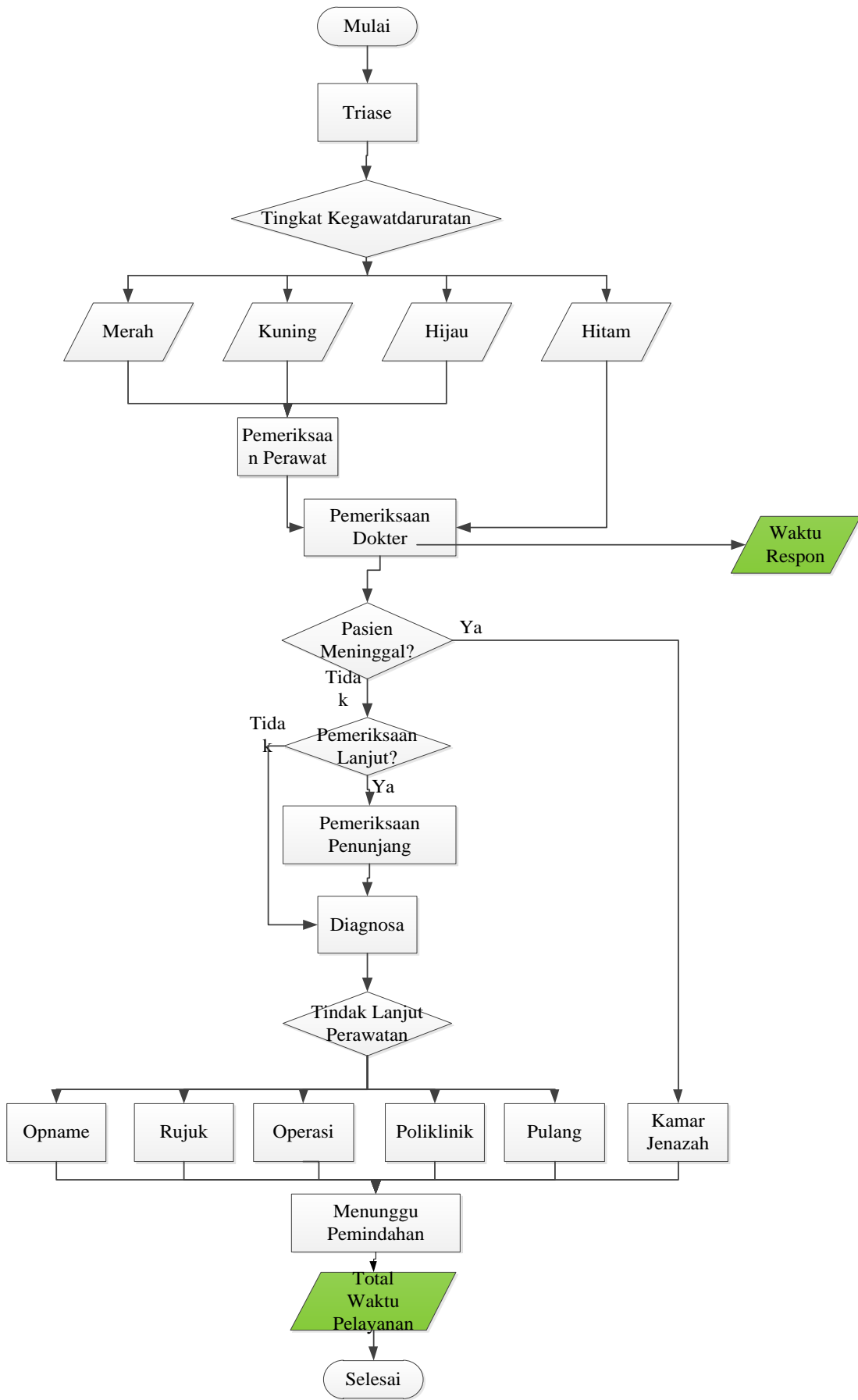

Gambar 1. Model konseptual proses pelayanan pasien

Model simulasi dibuat dengan menggunakan perangkat lunak simulasi Rockwell Arena berdasarkan model konseptual. Dalam pembuatannya, perlu dilakukan penyederhanaan model simulasi karena IGD RSU HKBP Balige termasuk ke dalam sistem yang sangat kompleks jika dimodelkan seluruhnya. Penyederhanaan model yang dilakukan dalam penelitian ini adalah sebagai berikut:

a. Sumber daya yang dimasukkan dalam model simulasi adalah sumber daya yang ada pada konteks sistem. Namun sumber daya yang diamati adalah sumber daya manusia yang ada di IGD, yaitu dokter IGD dan perawat IGD. Sarana prasarana IGD tidak diamati karena tidak berpengaruh secara signifikan terhadap waktu respon. Sedangkan sumber daya dari unit lain tidak diamati karena berada di luar IGD. 
b. Ruang triase, ruang pediatric anak, ruang trauma, ruang observasi dan ruang resusitasi pada model simulasi dijadikan ruang pemeriksaan. Hal ini dikarenakan keempat ruangan tersebut tidak memiliki fungsi yang berbeda pada kondisi nyata.

c. IGD RSU HKBP Balige saat pengambilan data dan pemodelan simulasi berada pada keadaan di mana seluruh sumber daya dapat digunakan dengan baik.

d. Pasien yang datang ke IGD hanya berjumlah satu orang per kedatangan

e. Jumlah sumber daya dari unit selain IGD tidak akan ditentukan jumlah kebutuhannya.

f. Lama waktu perjalanan pasien dari satu tempat ke tempat selanjutnya sudah termasuk ke dalam data waktu pengamatan. Contohnya, pasien yang perlu pindah dari ruang pemeriksaan ke ruang radiologi. Waktu untuk perpindahan pasien tersebut akan dimasukkan ke dalam waktu pelayanan pasien di ruang radiologi.

\subsection{Data Input}

Data input dalam model simulasi terdiri dari data sumber daya IGD RSU HKBP Balige, distribusi waktu kedatangan pasien, waktu pelayanan pasien, persentase pasien IGD untuk setiap tingkat kegawatdaruratan, persentase pasien yang meninggal dan yang tidak meninggal, persentase pasien yang mengikuti pemeriksaan penunjang, persentase pasien yang mengikuti setiap jenis pemeriksaan penunjang, persentase dokter IGD yang melakukan konsultasi dengan dokter spesialis dan persentase pasien untuk setiap tindak lanjut perawatan. Rekaman terhadap 212 pasien telah dipakai sebagai data input. Berdasarkan hasil uji distribusi diperoleh bahwa waktu kedatangan pasien berdistribusi Weibull, yaitu -0.001 + WEIB (43.7, 0.858); yang bearti distribusi waktu kedatangan pasien memiliki alpa sebesar 0.858 menit dan beta sebesar 43.7 menit dengan faktor penambah sebesar -0.001 menit. Waktu yang dibutuhkan untuk melakukan proses triase adalah 3 detik atau 0,05 menit. Distribusi waktu antara pasien tiba di IGD hingga pasien menempati bed di ruang pemeriksaan adalah distribusi Beta, yaitu $-0.001+0.991 * \operatorname{BETA}(1.37$, 1.62). Prosentase pasien berdasarkan kegawatdaruratan merah, kuning, hijau dan hitam masingmasing adalah 1,88\%, 71,70\%, 25,94\%, dan 0,47\%. Distribusi dan parameter distribusi dari waktu proses pemeriksaan perawat, dokter, dan tindakan tersebut diberikan dalam Tabel 2.

Tabel 2: Distribusi data waktu proses pemeriksaan perawat, dokter dan tindakan lanjut perawat

\begin{tabular}{|c|c|c|c|c|}
\hline Variabel & Merah & Kuning & Hijau & Hitam \\
\hline Waktu Proses & $0.5+$ & $0.5+$ & $0.5+$ & 0 \\
\hline $\begin{array}{l}\text { Pemeriksaan } \\
\text { Perawat } \\
\text { (menit) }\end{array}$ & $7 * \operatorname{BETA}(0.985,0.831)$ & $\begin{array}{l}\operatorname{ERLA}(0.842, \\
4)\end{array}$ & $\begin{array}{l}\text { WEIB }(2.82,1 . \\
36)\end{array}$ & \\
\hline $\begin{array}{l}\text { Waktu Proses } \\
\text { Pemeriksaan } \\
\text { Dokter (menit) }\end{array}$ & $\begin{array}{l}11.5+ \\
18 * \operatorname{BETA}(0.256 \\
0.303)\end{array}$ & $\begin{array}{l}0.5+ \\
\operatorname{ERLA}(1.67, \\
3)\end{array}$ & $\begin{array}{l}0.5+ \\
\text { ERLA(1.21, } \\
\text { 3) }\end{array}$ & 5 \\
\hline $\begin{array}{l}\text { Waktu Proses } \\
\text { Tindakan } \\
\text { Lanjut Perawat } \\
\text { (menit) }\end{array}$ & $\begin{array}{l}0.5+27 * \\
\operatorname{BETA}(0.459,0.333)\end{array}$ & $\begin{array}{l}0.5+ \\
\operatorname{GAMM}(3.36, \\
2.24)\end{array}$ & $\begin{array}{l}-0.5+ \\
\operatorname{LOGN}(4.55, \\
3.35)\end{array}$ & 1 \\
\hline
\end{tabular}

Dari 212 pasien yang diamati, terdapat 153 pasien $(72,16981132 \%)$ yang mengikuti pemeriksaan penunjang, baik tes lab, EKG maupun rontgen. Adapun prosentase pasien yang menjalani masingmasing pemeriksaan penunjang dan distribusi waktu prosesnya diberikan dalam Tabel. 3

Tabel 3: Prosentase dan distribusi data waktu proses pemeriksaan penunjang

\begin{tabular}{llll}
\hline Variabel & Tes Lab & EKG & Rontgen \\
\hline Prosentase (\%) & 90,20 & 23,53 & 11,76 \\
Waktu Proses & $13.5+23 * \operatorname{BETA}(4.64$, & $3.5+3 * \operatorname{BETA}(1.2$, & POIS $(18.1)$ \\
& $4.18)$ & $1.5)$ & \\
\hline
\end{tabular}


Persentase dokter IGD yang melakukan konsultsi dengan dokter spesialis adalah 1,88\% dengan waktu konsultasi rata-rata 5 menit. Waktu yang dibutuhkan untuk proses diagnosa adalah berdistribusi Lognormal dengan parameter 3.5+LOGN(3.47, 2.25). waktu yang dibutuhkan untuk proses advice dokter adalah berdistribusi Gamma dengan parameter $0.5+\operatorname{GAMM}(0.441,3.5)$. Prosentase pasien berdasarkan tindak lanjut perawatan dan distribusi waktu pemindahannya diberikan dalam Tabel 4.

Tabel 4: Prosentase dan distribusi data waktu tindak lanjut

\begin{tabular}{lcl}
\hline Jenis Tindak Lanjut & Prosentase $(\%)$ & Waktu Pemindahan $(m e n i t)$ \\
\hline Opname & 56,19 & $4.5+\operatorname{GAMM}(7.59,2.06)$ \\
Operasi & 0,48 & 127 \\
Poliklinik & 1,90 & $0.5+4 * \operatorname{BETA}(0.812,0.837)$ \\
Rujuk & 2,38 & $23+\operatorname{WEIB}(20.6,0.363)$ \\
Pulang & 39,04 & $0.5+\operatorname{LOGN}(10.2,12.9)$ \\
Kamar Jenazah & & TRIA $(0.5,1.5,2.5)$ \\
\hline
\end{tabular}

\subsection{Eksperimen}

Dengan menggunakan data input pada Bagian 3.4, didapatkan hasil simulasi awal terhadap waktu respon dan waktu pelayanan yang ditunjukkan dalam Tabel 5.

Tabel 5. Hasil simulasi awal

\begin{tabular}{lcc}
\hline \multicolumn{1}{c}{ Variabel } & Rata-rata & Maksimum \\
\hline Waktu respon (menit) & 4,95 & 25,10 \\
Waktu pelayanan (menit) & 91,76 & 345,63 \\
\hline
\end{tabular}

Pada di atas dapat dilihat bahwa waktu respon rata-rata adalah 4,95 menit dan waktu respon maksimum bernilai 25,10 menit. Hal ini tidak sesuai dengan standar waktu respon yang ditetapkan pada Keputusan Menteri Kesehatan Republik Indonesia Nomor 856 Tahun 2009, dimana waktu respon tidak boleh lebih dari 5 menit. Oleh karena itu, perlu dilakukan eksperimen untuk mencari jumlah sumber daya manusia yang optimal dalam mempercepat waktu respon agar sesuai dengan standar. Kemudian dilakukan 5 eksperimen secara iterative dengan desain matrik dimana setiap desain matriks terdiri dari 4 skenario. Skenario-skenario selanjutnya ditentukan berdasarkan desain matriks $2 \mathrm{k}$ pada Tabel 21. Tanda (+) berarti jumlah sumber daya pada skenario tersebut merupakan jumlah sumber daya dari skenario 1 ditambah 1 , sedangkan tanda (-) berarti jumlah sumber daya pada skenario tersebut sama dengan sumber daya pada skenario 1. Eksperimen didesain menggunakan desain faktorial $2^{\mathrm{k}}$ dengan $\mathrm{k}=2$ faktor input, yaitu dokter dan perawat. Eksperimen dilakukan dengan menjalankan simulasi dengan kombinasi faktor input sesuai dengan desain matriks $2^{\mathrm{k}}$ dengan matriks desain eksperimen.

Tabel 5. Desain matriks eksperimen

\begin{tabular}{ccc}
\hline Skenario & Dokter & Perawat \\
\hline 1 & - & - \\
2 & + & - \\
3 & - & + \\
4 & + & + \\
\hline
\end{tabular}

Pada eksperimen 1, kombinasi sumber daya yang menjadi dasar skenario 1 adalah kombinasi sumber daya saat keadaan normal, yaitu 1 dokter dan 3 perawat. Hasil dari eksperimen 1 menunjukkan bahwa skenario yang menghasilkan nilai waktu respon rata-rata terkecil adalah scenario 4 , yaitu 2 dokter dan 4 perawat. Nilai waktu respon rata-rata berkurang secara signifikan dari keadaan normal (skenario 1) 8,61 menit menjadi 4,76 menit. Selain itu, nilai total waktu 
pelayanan rata-rata pada scenario 4 juga merupakan nilai terkecil di antara nilai total waktu pelayanan rata-rata pada skenario lainnya, yaitu 62,59 menit. Oleh karena itu, dapat disimpulkan bahwa skenario terbaik pada eksperimen 1 adalah skenario 4 .

Pada eksperimen 2, kombinasi sumber daya manusia yang menjadi skenario 1 adalah kombinasi sumber daya terbaik pada eksperimen sebelumnya (eksperimen 1), yaitu skenario 4 dengan 2 dokter dan 4 perawat. Hasil dari eksperimen 2 menunjukkan skenario yang menghasilkan nilai waktu respon rata-rata terkecil adalah skenario 2 dan 4 . Nilai waktu respon rata-rata berkurang dari 4,76 menit menjadi 4,16 menit. Dengan melihat bahwa nilai waktu respon maksimum dan total waktu pelayanan maksimum pada skenario 4, yaitu 14,09 menit dan 383,84 menit, yang merupakan nilai terkecil di antara skenario lainnya, maka disimpulkan bahwa skenario terbaik pada eksperimen 2 adalah skenario 4 .

Pada eksperimen 3, kombinasi sumber daya manusia yang menjadi skenario 1 adalah kombinasi sumber daya terbaik pada eksperimen sebelumnya (eksperimen 2), yaitu skenario 4 dengan 3 dokter dan 5 perawat. Hasil dari eksperimen 3 menunjukkan bahwa skenario yang menghasilkan nilai waktu respon rata-rata terkecil adalah skenario 3 dan 4 . Nilai waktu respon rata-rata berkurang dari 4,16 menit menjadi 4,14 menit. Nilai waktu respon maksimum pada skenario 3 juga merupakan nilai terkecil dan tidak berubah dari skenario 1, yaitu 14,09 menit. Nilai total waktu pelayanan maksimum pada skenario 3 juga merupakan nilai terkecil, yaitu 381,97 menit. Oleh karena itu, dapat disimpulkan bahwa skenario terbaik pada eksperimen 3 adalah skenario 3 .

Pada eksperimen 4, kombinasi sumber daya manusia yang menjadi skenario 1 adalah kombinasi sumber daya terbaik pada eksperimen sebelumnya (eksperimen 3), yaitu skenario 3 dengan 3 dokter dan 6 perawat. Hasil dari eksperimen 4 menunjukkan bahwa semua skenario menghasilkan nilai waktu respon rata-rata yang sama, yaitu 4,14 menit. Nilai waktu respon maksimum dan total waktu pelayanan maksimum terkecil juga sama dengan nilai pada kombinasi 1, masing-masing 14,09 dan 381,97 menit. Oleh karena itu, dapat disimpulkan bahwa skenario terbaik pada eksperimen 4 adalah skenario 1.

Eksperimen 5 bertujuan untuk melihat apakah penambahan sumber daya manusia masih dapat menurunkan waktu respon rata-rata atau waktu respon maksimum. Oleh karena itu, pada eksperimen 5 kombinasi sumber daya manusia yang menjadi skenario 1 adalah kombinasi sumber daya terbanyak pada eksperimen sebelumnya (eksperimen 4), yaitu skenario 4 dengan 4 dokter dan 7 perawat. Hasil dari eksperimen 5 menunjukkan bahwa semua skenario menghasilkan nilai waktu respon rata-rata yang sama, yaitu 4,14 menit. Oleh karena nilai waktu respon dan waktu pelayanan sudah tidak dapat menurun lagi, maka eksperimen tidak dilanjutkan lagi.

Tabel 6: Jumlah dokter dan perawat untuk masing-masing eksperimen dan skenario

\begin{tabular}{cccllllllll}
\hline & \multicolumn{1}{l}{ Eksp. 1 } & \multicolumn{2}{l}{ Eksp. 2 } & \multicolumn{3}{l}{ Eksp. 3 } & \multicolumn{2}{c}{ Eksp. 4 } & \multicolumn{2}{c}{ Eksp. 5 } \\
\hline Skenario & D & P & D & P & D & P & D & P & D & P \\
\hline 1 & 1 & 3 & 2 & 4 & 3 & 5 & 3 & 6 & 4 & 7 \\
2 & 2 & 3 & 3 & 4 & 4 & 5 & 4 & 6 & 5 & 7 \\
3 & 1 & 4 & 2 & 5 & 3 & 6 & 3 & 7 & 4 & 8 \\
4 & 2 & 4 & 3 & 5 & 4 & 6 & 4 & 7 & 5 & 8 \\
\hline D = Jumlah dokter (orang) \\
P = Jumlah perawat (orang)
\end{tabular}


Tabel 7: Waktu respon dan waktu pelayanan hasil simulasi

\begin{tabular}{|c|c|c|c|c|c|c|c|c|c|c|}
\hline \multirow[b]{2}{*}{ Skenario } & \multicolumn{2}{|c|}{ Eksp. 1} & \multicolumn{2}{|c|}{ Eksp. 2} & \multicolumn{2}{|c|}{ Eksp. 3} & \multicolumn{2}{|c|}{ Eksp. 4} & \multicolumn{2}{|c|}{ Eksp. 5} \\
\hline & WR & WP & WR & WP & WR & WP & WR & WP & WR & WP \\
\hline 1 & 8,61 & 164,92 & 4,76 & 62,59 & 4,16 & 63,20 & 4,14 & 63,18 & 4,14 & 62,66 \\
\hline 2 & 4,95 & 91,76 & 4,16 & 63,12 & 4,16 & 62,54 & 4,14 & 62,66 & 4,14 & 62,74 \\
\hline 3 & 7,90 & 157,41 & 4,21 & 63,03 & 4,14 & 63,18 & 4,14 & 63,18 & 4,14 & 62,66 \\
\hline 4 & 4,76 & 62,59 & 4,16 & 63,20 & 4,14 & 62,66 & 4,14 & 62,66 & 4,14 & 62,74 \\
\hline
\end{tabular}

\subsection{Analisis Hasil Akhir}

Dari hasil simulasi dalam beberapa eksperimen yang telah dilakukan, didapatkan fakta bahwa dalam berbagai skenario yang diujikan waktu respon terkecil yang berhasil didapatkan adalah 4,14 menit, yaitu pada eksperimen 3 skenario 3 ( 3 dokter dan 6 perawat), eksperimen 4 semua skenario (3-4 dokter dan 6-7 perawat), dan experiment 5 semua skenario (4-5 dokter, 7-8 perawat). Namun demikian untuk mencapai target standard waktu respon sesuai peraturan yang berlaku $(<5$ menit), dapat dipenuhi dalam eksperimen 1 skenario 2 ( 2 dokter dan 3 perawat). Sesuai dengan tujuan yang ingin dicapai dalam simulasi ini, yaitu membuat keputusan mengenai jumlah dokter dan perawat yang optimal dalam mencapai target standard waktu respon sesuai peraturan yang berlaku, dengan demikian kombinasi sumber daya dalam eksperimen 1 skenario 2 ( 2 dokter dan 3 perawat) diputuskan menjadi rekomendasi yang diberikan kepada IGD RSU HKBP Balige untuk dapat diimplementasikan.

\section{Kesimpulan}

Berdasarkan penelitian yang dilakukan dengan metode Discrete Event Simulation untuk menentukan jumlah kebutuhan sumber daya manusia di IGD RSU HKBP Balige, maka disimpulkan sebagai berikut:

1. Jumlah dokter dan perawat yang optimal agar waktu respon rata-rata sesuai dengan standar $(<5$ menit) adalah 2 dokter dan 3 perawat. Waktu respon rata-rata dengan scenario ini adalah 4,95 menit.

2. Telah dihasilkan model simulasi untuk menentukan jumlah kebutuhan sumber daya IGD yang dapat digunakan untuk keperluan perencanaan sumber daya manusia selanjutnya apabila terjadi perubahan distribusi variable-variabel sistem (jumlah pasien, waktu penanganan, dll)

3. Penelitian ini memberikan kontribusi terhadap ilmu pengetahuan sebagai referensi penerapan aplikasi DES dalam mendukung keputusan perencanaan sumber daya manusia di IGD rumah sakit.

4. Penelitian selanjutnya dapat diarahkan untuk juga mempertimbangkan sumber daya lain seperti ketersediaan alat-alat medis agar lebih komprehensif.

\section{Referensi}

[1] American College of Emergency Physicians, "Clinical Policy: Critical Issues in the Evaluation and Managent of Adult Patients Presenting with Suspected Acute Myocardial Infarction or Unstable Angina", Ann Emerg Med, vol. 35, no. 5, pp. 521-544, May 2000, doi: 10.1067/mem.2000.106387

[2] Blasak, R, D. Starks, A. Wendy and M. Hayduk, "The use of simulation to evaluate hospital operations between the emergency department and a medical telemetry unit" Proc. 2003 Winter Simulation Conf., S. Chick, P. J. Sanchez, D. Ferrin, and D. J. Morrice (eds), pp. 1887-1893, 2003 
[3] Kelton, W., R. Sadowski, and N. Zupick, "Simulation with Arena $6^{\text {th }}$ ed." McGraw-Hill Education 656p., Jan 2014

[4] Mahapatra S., C. Koelling, L. Patvivatsiri, B. Fraticelli, D. Eitel, L. and Grove, "Pairing emergency severity index-level triage data with computer aided system design to improve emergency department access and throughput" Proc. 2003 Winter Simulation Conf., S. Chick, P. J. Sanchez, D. Ferrin, and D. J. Morrice (eds), pp. 1917-1925, 2003

[5] Menteri Kesehatan Republik Indonesia, "Keputusan Menteri Kesehatan Republik Indonesia Nomor 856/Menkes/SK/IX/2009 tentang Standar Instalasi Gawat Darurat (IGD) Rumah Sakit", Sept. 2009

[6] Nahhas, A., A. Awaldi, \& T. Reggelin, "Simulation and the Emergency Department Overcrowding Problem". Procedia Eng, vol. 178, pp. 368-376, Nov 2017, doi: 10.1016/j.proeng.2017.01.068

[7] Rado, O., B. Lupia, J. Leung, Y. Kuo, C. Graham, "Using simulation to analyze patient flows in a hospital emergency department in Hong Kong". Proc. Int. Conf. on Health Care Syst. Eng. pp. 289-301.2014

[8] Samaha, S, A. Wendy and S. Darrell, 2003. "The use of simulation to reduce the length of stay in an emergency department" Proc. 2003 Winter Simulation Conf., S. Chick, P. J. Sanchez, D. Ferrin, and D. J. Morrice (eds), pp. 1907-1911, 2003

[9] Yang, K. K., S. Lam, J. Low, M. Ong, "Managing emergency department crowding through improved triaging and resource allocation" Opr. Res. for Health Care, vol. 10, pp. 13-22, Sept. 2016, doi: 10.1016/j.orhc.2016.05.001 